\title{
Nutrition at retirement age
}

By M. Diane Holdsworth and Louise Davies, Gerontology Nutrition Unit, Queen Elizabeth College, University of London, Campden Hill, Kensington, London $W 87 A H$

Why is it important to investigate the nutrition and wellbeing of men and women at the age of retirement from work? Surely by this time their meal patterns and food choice are already set, and it would seem more important to influence those at a younger age.

Nevertheless, retirement from work is a time when food habits may change: former employees no longer eat at their place of work, food shopping patterns may alter (possibly because of a fall in income), meal times and meal companions could be different. If steps towards healthier eating could be encouraged at this time of change, habits which are conducive to positive health could be built into this new lifestyle. Moreover, at retirement from work people are likely to be concerned about their present and future health, therefore any programme for preventive care implemented at this stage in life could reach a target group which is highly motivated.

In a study of the nutrition of people approaching retirement, we found that it is not easy to conduct a survey among people who are still at work. The permission of the employers for time off with pay needs to be obtained. The employees themselves may reckon that they are too busy to co-operate. Another major difficulty was that most firms would, understandably, refuse permission for outsiders to contact their staff direct. The potential sample had to be approached via the personnel officers. Due to this it was not possible to find the reasons for refusal to participate. Some may have been daunted by the prospect of losing time off work, or having a medical screening; on the other hand, others may have been attracted by such requests.

\section{The sample and plan of research}

Firms need to be extremely large in order to have sufficient numbers retiring each year. Eventually employees from two firms co-operated; they had to be unconnected with the food industry in case this should affect their nutritional knowledge or food choice. The total sample of 213 men and women closely approximated the national average for socio-economic groups and the sex ratios within the general work force.

At stage I of our longitudinal survey, base-line data were collected approximately I year before the subjects' date of retirement. Approximately 6 months later, nutritional counselling was given to half the sample (Davies \& Holdsworth, 1983). In the current longitudinal phase of the survey, subjects are 
returning for repeat investigations not less than 6 months after their retirement date.

Within the research programme the same individuals are being studied at two vital periods in their life, and changes are being monitored. The present paper presents findings from the completed base-line pre-retirement data.

For an investigation of this age-group it was considered important to examine such topics as physical activity, past and present smoking habits, alcohol consumption, stress factors and attitudes to retirement, as well as the nutritional concerns such as shopping habits, meal patterns and dietary intake. In order to obtain such full details, questionnaires were designed to flow as a guided conversation lasting approximately $\mathrm{I} \cdot 5 \mathrm{~h}$. In addition, frequency of consumption lists were designed. The consumption of specific foods was coded as daily, weekly, fortnightly, monthly, occasionally, rarely or never. Thus some idea of foods eaten throughout the year could be obtained. This information is not necessarily indicated in the normal dietary recalls or I week's weighed dietary records.

It was necessary to use a standardized technique for measuring stress. We therefore chose the Goldberg (1978) General Health Questionnaire which had been extensively researched to identify somatic symptoms, anxiety and insomnia, social dysfunction and severe depression. It consists of up to sixty questions with four scales of response for each question.

All the previously mentioned information was obtained from the total sample of 213 men and women. In addition, the 113 subjects from firm 1 agreed to further investigations which consisted of:

I. A health screening at the British United Provident Association (BUPA) private medical centre in London. This included routine medical blood analyses.

2. Further biochemical analyses for assessment of nutritional status.

3. A $7 \mathrm{~d}$ weighed and recorded dietary intake.

As with all nutritional surveys, much time needs to be spent encouraging the sample to meet the demands imposed. Public relations, personal encouragement, motivation and written instructions are important in surveys of this type.

The dietary weighing and recording was taught during a picnic-style lunch at the medical centre. Checks were made on the validity of the I week's weighed records by using simultaneously four methods of estimating food intakes (Holdsworth et al. 1984). These methods were: (a) I week's weighed and recorded dietary intakes examined in conjunction with (b) frequency of consumption lists; (c) recall of food and drink customarily consumed (this was not the usual $24 \mathrm{~h}$ recall but rather an example of eating and drinking style throughout a normal day); (d) carefully-designed questions within the main questionnaire on the consumption of, for example, alcohol, butter, margarine, breads, and the use of the salt cellar.

\section{General findings compared with recommendations}

The present paper compares some of our general findings with recommendations made in recent reports such as the National Advisory Committee on Nutrition 
Table $\mathrm{r}$. The choice of butter or margarine with bread: men aged $63-64$ years and women aged ${ }^{8}{ }^{-}-59$ years ( $\left.\mathrm{n} 2 \mathrm{I}_{3}\right)$

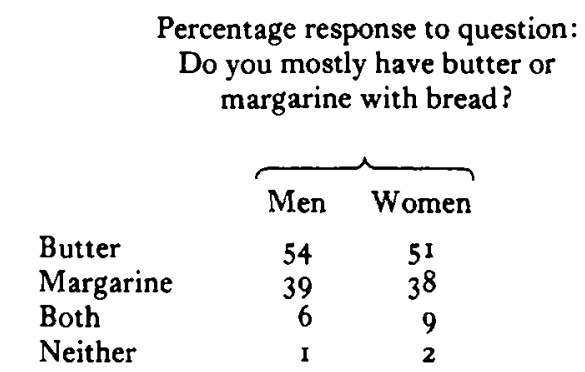

Education ( $\mathrm{I}^{8} 8_{3}$ ) discussion document; the 'Obesity Report' (Royal College of Physicians, 1983) and the report on 'Alcohol and Alcoholism' (Special Committee of the Royal College of Psychiatrists, 1979). Our data included general information about the shopping and eating styles of the total sample of 213 , i.e. 136 men and 77 women. This is the generation who were not brought up in the age of supermarkets but it was obvious that new shopping styles, at least in London and its outskirts, had been adopted: $93 \%$ bought their food from supermarkets although $4 \mathrm{I} \%$ also regularly used a small grocer.

Food choice, however, may tend to cling to traditions laid down in youth, and this may prove of importance in implementing future nutritional guidelines. It may have been the habit of a lifetime that kept up the popularity of butter as shown in the response to the question in Table $\mathrm{I}$.

However, the tradition of the Great British Breakfast does seem to have changed. Concern is sometimes expressed at the number of schoolchildren who skip breakfast (Bender et al. 1972). The men and women in our study were old enough to be grandparents. They were asked whether they ate breakfast, either cooked or uncooked. Table 2 indicates that as many as $25 \%$ did not eat breakfast every day.

Many of the subjects were weight-conscious: $45 \%$ reckoned that they had a tendency to overweight. To the question, 'in the past year have you been altering what you eat in order to control your weight ?' $35 \%$ responded yes, representing $29 \%$ of the men and $46 \%$ of the women. This may have influenced the fact that so

Table 2. Breakfast habits of men aged $63^{-6}-4$ years and women aged $5^{8-59}$ years

\begin{tabular}{|c|c|c|}
\hline & \multicolumn{2}{|c|}{$\begin{array}{c}\text { Percentage eating } \\
\text { breakfast }\end{array}$} \\
\hline & Men & Women \\
\hline $\begin{array}{l}\text { Every day } \\
\text { Weekdays only }\end{array}$ & $\begin{array}{r}74 \\
2\end{array}$ & $\begin{array}{r}75 \\
0\end{array}$ \\
\hline Weekends only & 10 & 5 \\
\hline Sometimes & 4 & 8 \\
\hline Never & ro & 12 \\
\hline
\end{tabular}


Table 3. Sugar taken in tea and coffee by men aged $6_{3}-64$ years and women aged $5^{8-59}$ years (\% of total) (n 213)

$\begin{array}{lrc} & \text { Tea } & \text { Coffee } \\ 0.5 \text { teaspoon } & 5 & 5 \\ \text { 1 teaspoon } & 17 & 24 \\ 2 \text { teaspoons } & 14 & 18 \\ 3 \text { teaspoons } & 2 & 3 \\ \text { None } & 62 & 50\end{array}$

many of them drank tea and coffee without sugar. The number of teaspoons of sugar taken in tea and coffee is shown in Table 3 . For coffee $40 \%$ of the men and $65 \%$ of the women did not add sugar.

Given this type of response perhaps one should query the advisability of encouraging manufacturers to switch from sucrose to an artificial sweetener. It might be more acceptable to take advantage of the capacity of people to live with a less-sweet palate and to make products less sweet by reducing the sugar content. Certainly artificial sweetners were not popular in drinks; only $16 \%$ of the sample used them regularly, even though so many were trying to slim.

It may be relatively easy at the age of retirement to implement the guidelines recommending increased consumption of fruits and vegetables, and the importance of maintaining physical activity. Even before retiring from work, as many as $46 \%$ of the total sample were growing fruit or vegetables in their gardens or allotments.

\section{Findings from firm I including $I$ week's weighed dietary records}

From the medical screening and I week's weighed dietary records of the II 3 subjects from firm I, it was possible to study the prevalence of, for instance, hypertension, obesity, hypercholesterolaemia. We also wished to answer the following questions. Did their diet quantitatively show evidence of high fat, including animal fats, sugar, salt and alcohol intakes? Were they already having the low-potassium, low-fibre diets common amongst some elderly?

Raised blood pressure. Raised blood pressure was prevalent among our sample, especially the men: $4 \mathrm{I} \%$ had resting diastolic blood pressures above $90 \mathrm{~mm} \mathrm{Hg}$, $30 \%$ were above $95 \mathrm{~mm} \mathrm{Hg}$; for women the corresponding values were $\mathrm{I} 9$ and $7 \%$ (Fig. I). Of the men in the sample, $25 \%$ could be classified as hypertensive, with both a resting systolic blood pressure of $>_{1} 60 \mathrm{~mm} \mathrm{Hg}$ and a resting diastolic blood pressure of $>90 \mathrm{~mm} \mathrm{Hg}$.

Obesity. Using the quetelet index for body mass (weight $/$ height $^{2}$ ), Garrow ( $198 \mathrm{I}$ ) defines those with an index of $25-29.9$ as having grade I obesity, and $30-40$ as having grade II obesity, which is clinically serious. In our sample, $50 \%$ of the men had an index of between 25 and 29.9 and $11 \%$ an index of over 30 . For women in our sample, corresponding values were 40 and $6 \%$ respectively. Fig. 2 demonstrates the wide ranges from the very thin to the obese. 


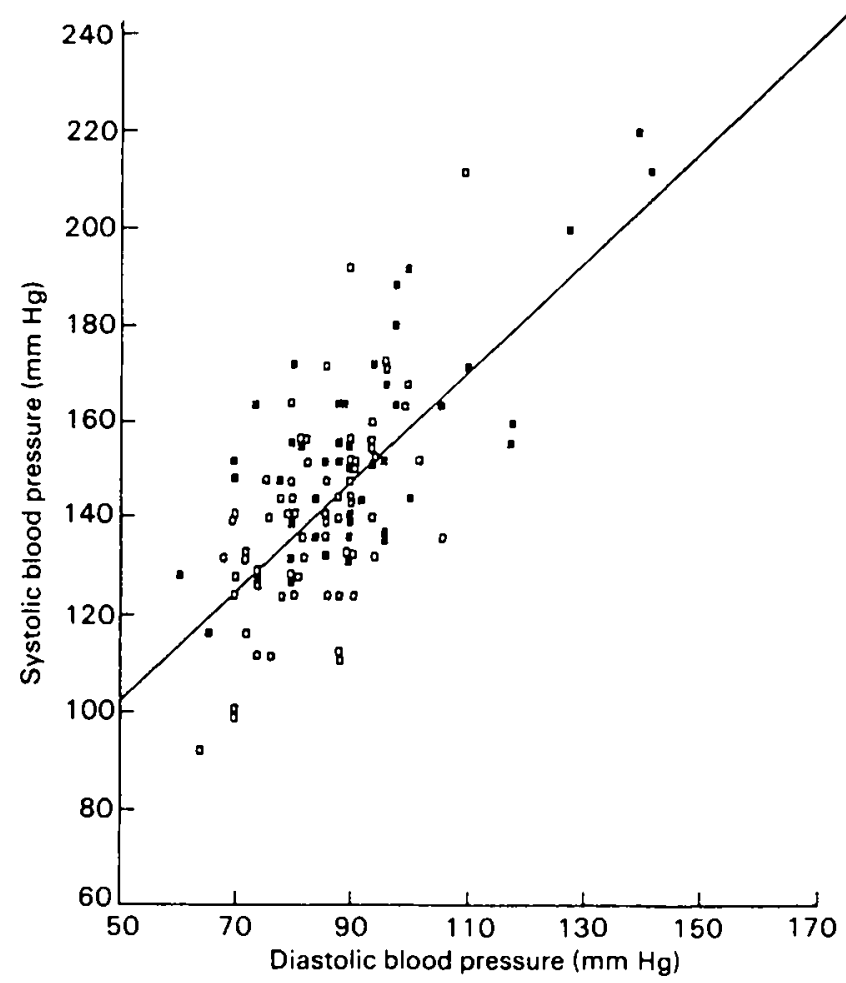

Fig. I. Resting diastolic and systolic blood pressure in a sample of men and women approaching retirement from work. (D) Men aged $63-64$ years, $n_{4} 6$; (D) women aged $5^{8}-59$ years, $n 67$.

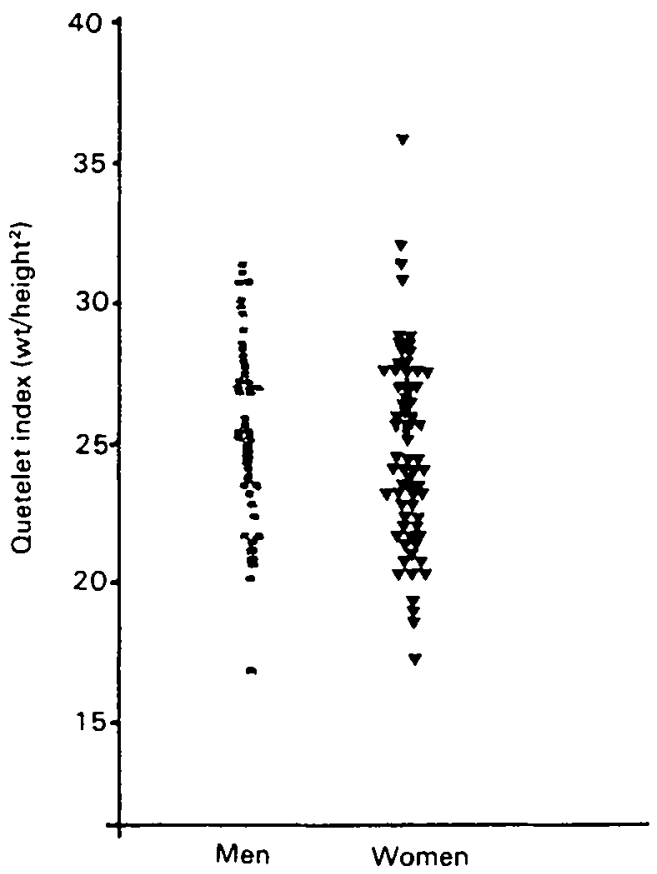

Fig. 2. Quetelet index (weight/height ${ }^{2}$ ) of men and women approaching retirement from work. ( $\square$ ) Men aged $63-64$ years, $n 46 ;(\nabla)$ women aged $58-59$ years, $n 67$. 
Raised serum cholesterol. Serum cholesterol values are shown in Fig. 3. The mean value for the men was $6.72 \mathrm{mmol} / 1$, and for the women $7 \cdot 16 \mathrm{mmol} / \mathrm{l}$. An average value below $5.2 \mathrm{mmol} / \mathrm{l}(2 \mathrm{~g} / \mathrm{l})$ is considered as low as is likely to be achieved in the UK (World Health Organization, I982).

A serum cholesterol concentration of $4-4.5 \mathrm{mmol} / 1(\mathrm{I} \cdot 6-\mathrm{I} \cdot 8 \mathrm{~g} / \mathrm{l})$ is associated with a very low risk of coronary heart disease (American Health Foundation, 1979). Only one of our subjects fell into this category.

Dietary fats. Our pre-retirement sample was from South-east England, where the incidence of coronary heart disease is high. There is a strong consensus of opinion that the incidence of coronary heart disease could be lowered by the reduction of total fat in the diet to $30-35 \%$ of total energy (Royal College of Physicians and British Cardiac Society, 1976). A recent, relatively small survey has suggested that in the diets of men within a wide age group living in South-east England, approximately $38 \%$ of their total energy was derived from fats (Bingham et al. 1980). For the men in our pre-retirement sample, the energy derived from fats was $4 \mathrm{I} \%$, for the women $43 \%$. However, energy derived from fats was recalculated at $43 \%$ for men and $44 \%$ for women when alcohol was excluded from the total energy intake. The percentage of energy from carbohydrate and protein was 39.1 and 15.8 respectively. These values correspond with the mean daily intakes of energy and nutrients shown in Table 4.

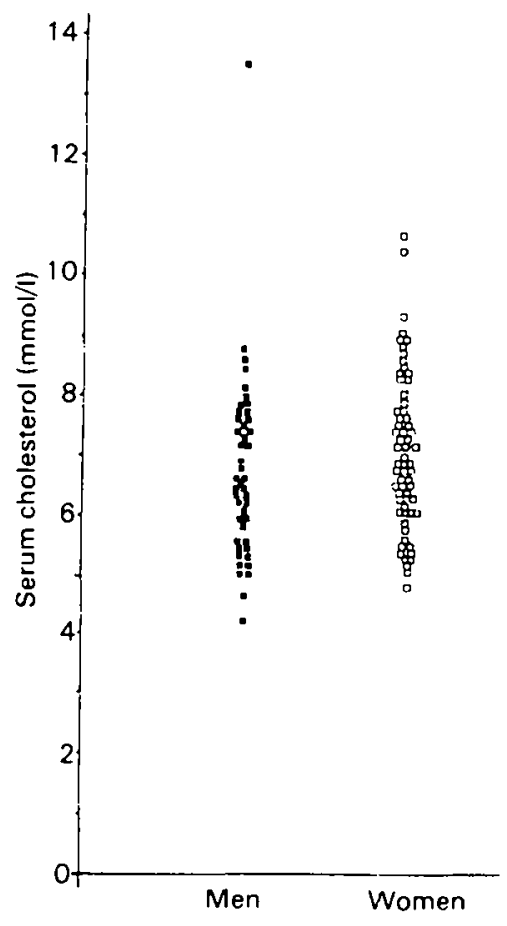

Fig. 3. Serum cholesterol values (mmol/l) in a sample of men and women approaching retirement from work. (ם) Men aged $63-64$ years, $n_{45} ;(\square)$ women aged $58-59$ years, $n 64$. 
Table 4. Daily intakes of energy (MY, kcal) and nutrients $(g)$ in men aged $6_{3}-6_{4}$ years $(\mathrm{n} 46)$ and women aged $5^{8-59}$ years ( $\mathrm{n}_{56}$ )

(Values in parentheses indicate values when abstainers are excluded)

\begin{tabular}{|c|c|c|c|c|c|c|c|}
\hline & \multicolumn{2}{|c|}{ Energy intake } & \multirow[t]{2}{*}{ Protein } & \multirow[t]{2}{*}{ Fat } & \multirow[t]{2}{*}{ Carbohydrate } & \multirow[t]{2}{*}{ Alcohol } \\
\hline & & (MJ) & (kcal) & & & & \\
\hline \multirow[t]{2}{*}{ Mean } & Men & 10.0 & 2392 & $90 \cdot 0$ & 109 & 256 & $12(16 \cdot 7)$ \\
\hline & Women & $7 \cdot 2$ & 1728 & 710 & 82 & 174 & $7(11 \cdot 2)$ \\
\hline \multirow[t]{2}{*}{ Range } & Men & $6 \cdot 8-17.6$ & $1622-4209$ & $59 \cdot 1-15^{8 \cdot 3}$ & $34-231$ & $86-452$ & $0-100(0.6-100)$ \\
\hline & Women & $3 \cdot 0-11 \cdot 0$ & $721-2642$ & $34 \cdot 8-96 \cdot 3$ & $34-128$ & $68-293$ & $0-60(0 \cdot 2-60)$ \\
\hline \multirow[t]{2}{*}{ SD } & Men & $21 \cdot 6$ & 515 & 20.8 & $32 \cdot 5$ & 75 & $19(20.9)$ \\
\hline & Women & 16.8 & 402 & 13.1 & 20.6 & 54 & $\operatorname{II}(12 \cdot 0)$ \\
\hline \multirow[t]{2}{*}{$\mathrm{RDA}$} & Men & 10.0 & 2400 & 60 & - & - & - \\
\hline & Women & $8 \cdot 0$ & 1900 & 47 & - & - & - \\
\hline
\end{tabular}

RDA, recommended daily amounts (Department of Health and Social Security, 1979).

Approximately $75 \%$ of the ingested fats came from animal sources: among the contributions to total fat were meat and meat dishes $24.2 \%$, milks $8.9 \%$, other dairy products (including butter) $22.9 \%$.

There were several blatant examples of a high fat intake resulting from misinterpretations of low-carbohydrate slimming diets. In the diet record of one woman was written 'I Energen roll spread thickly with butter'; another woman recorded 'Nimble bread $5 / 6$ oz and then as much as $2 / 3$ oz butter and $I \frac{1}{3}$ oz jam'.

Sugar and salt intakes. In the sample, sugar contributed $12.2 \%$ of total energy intake. Those who routinely sweetened their beverages could be advised simply to reduce the amount.

It is recognized that food manufacturers have a responsibility in helping to diminish sodium intakes. However, our results also indicate the need for health education for people at retirement age on the use of table salt. The majority customarily added salt to the food once it was on the plate, as shown in Table 5 .

Potassium and dietary fibre. The preliminary findings indicated, for men, a weak inverse relationship between dietary $\mathrm{K}$ intake and diastolic blood pressure (Fig. 4). This finding was not statistically significant (correlation coefficient $-0.2 \mathrm{I}$ ). However, it is noteworthy that the men who were hypertensive (indicated in Fig. 2) were among those with the lowest dietary $\mathrm{K}$ intakes. The mean daily dietary $\mathrm{K}$ intake was: hypertensive men $64 \mathrm{mmol}(\mathrm{z} \cdot 5 \mathrm{~g})$; those classified as not hypertensive $87 \mathrm{mmol}(3.4 \mathrm{~g})$. For the men in our sample, fruit and vegetable

Table 5. Salt added to food on the plate by men aged $63-64$ years and women aged $5^{8-59}$ years (\% of total) ( $\left.\mathrm{n} \times 13\right)$

$\begin{array}{ll}\text { Always } & 50 \\ \text { Often } & 11 \\ \text { Occasionally } & 15 \\ \text { Seldom } & 11 \\ \text { Never } & 13\end{array}$




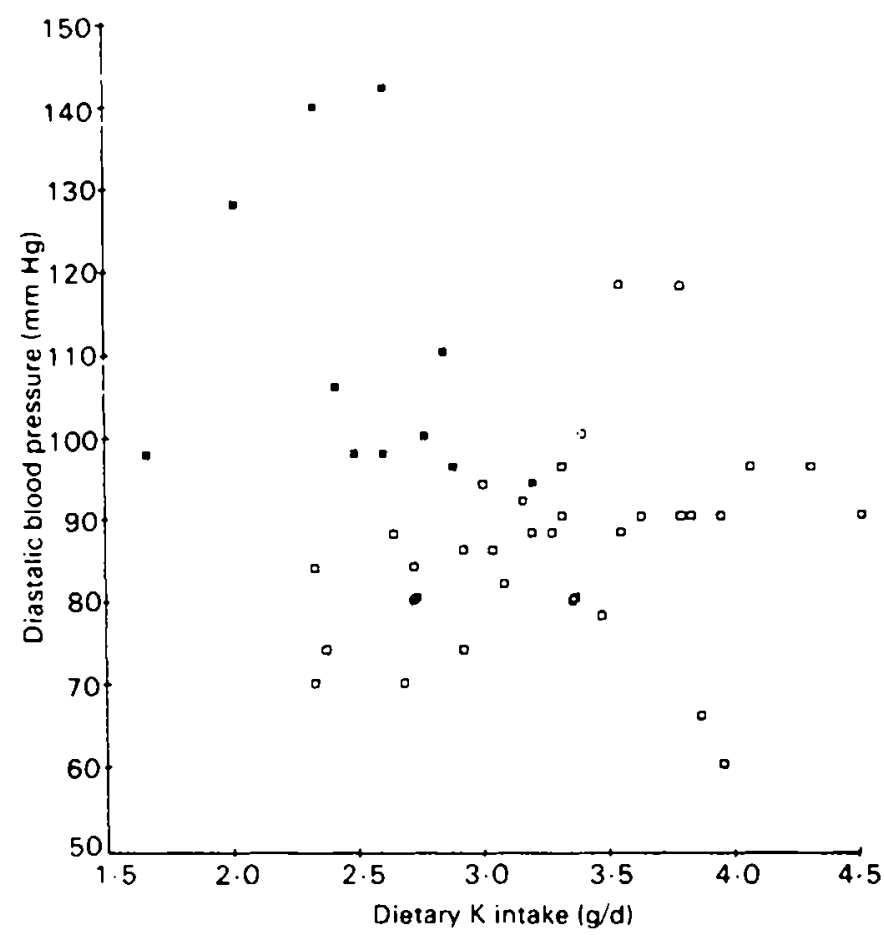

Fig. 4. Dietary potassium intakes $(\mathrm{g} / \mathrm{d})$ and diastolic blood pressure $(\mathrm{mm} \mathrm{Hg})$ of men approaching retirement from work (aged $6_{3}-6_{4}$ years, $n_{4} 6$ ). (D), Men with systolic blood pressure $>160 \mathrm{~mm} \mathrm{Hg}$.

consumption was negatively correlated with systolic blood pressure (correlation coefficient $-0.46, \mathrm{P}<0.001$ ) (Fig. 5).

Also of concern in the UK are low fibre intakes; the average British diet contains $20 \mathrm{~g}$ dietary fibre/d (Southgate et al. 1978) and it has been suggested that for adults this should be increased to $30 \mathrm{~g} / \mathrm{d}$ (National Advisory Committee on Nutrition Education, 1983 ). From our results the mean daily intake was only $18 \mathrm{~g}$ : men $19 \mathrm{~g}$ (range $8-36 \mathrm{~g}$ ); women $\mathrm{I} 6 \mathrm{~g}$ (range 7-35 $\mathrm{g}$ ). Of this sample, $94 \%$ were below the recommendation of $30 \mathrm{~g}$ dietary fibre/d.

In a survey on people about to retire, and thus alter their lifestyle, it is important to examine factors such as alcohol, smoking and exercise.

Alcohol. The Special Committee of the Royal College of Psychiatrists (1979) suggests that an intake of 4 pints of beer daily, or its equivalent, constitutes a reasonable guideline for the upper safe limit of drinking. Wilson (1980), conducting research on drinking in England and Wales, indicates heavy drinkers as those who consume over 50 units per week for men and over 35 units per week for women. This represents for men 3.5 pints of beer $(60 \mathrm{~g}$ alcohol) and for women 2.5 pints ( $4 \circ \mathrm{g}$ alcohol) daily, or its equivalent. It should be emphasized that these levels are not intended as suggestions for routine consumption.

The I week's weighed records of our subjects showed widely varying alcohol intakes, ranging from the expected zero to the high intake for one gentleman of 100 g daily. 


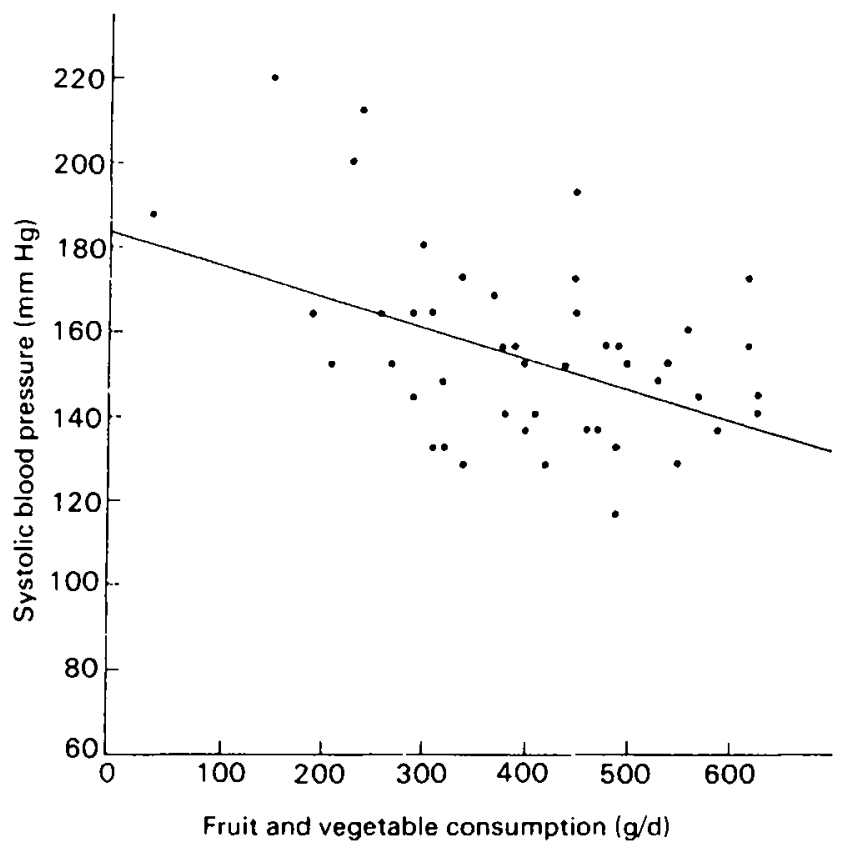

Fig. 5. Fruit and vegetable consumption ( $\mathrm{g} / \mathrm{d}$ ) and resting systolic blood pressure $(\mathrm{mm} \mathrm{Hg}$ ) of mean approaching retirement from work (aged $6_{3}-6_{4}$ years, $n_{4} 6$ ).

It was important for the interviewer to record on the questionnaire relevant comments from the subjects; these comments illuminated attitudes, e.g. the heaviest drinker (subject no. 103) stated that 'gin is a woman's drink; its alcohol effect on men is negligible'. When questioned further he gave the following answers: 'For lunch at work I often have no food, instead I have a gin ... about three pub measures, with a splash of martini to colour it. Then, maybe, I would have another such drink and sometimes a third. If I am thirsty I have 2 pints of beer afterwards. At dinner I share a bottle of wine with my wife (she has one glass). In the evening I often drink a bottle of wine also'. Interviewer: 'Do you ever have whisky?' Subject no. 103: 'No, most certainly not. I never touch the hard stuff'.

As could be expected his serum glutamic oxalacetic transaminase $(E C$ 2.6.1.1; SGOT) levels were markedly raised above a normal upper limit of $50 \mathrm{iu} / 1$ at 225 $\mathrm{iu} / \mathrm{l}$, and his $\gamma$-glutamyl transpeptidase ( $E C$ 2.3.2.2; GGT) activity was ninefold greater than the upper limits of normal. Of our sample, $3 \%$ had raised SGOT levels. $32 \%$ of our total sample of 2 I 3 said they would take a drink 'most days'. In contrast, over half the sample were infrequent drinkers (Fig. 6).

The average weekly intake of the $68 \%$ of the sample who consumed alcohol during the week of their weighed dietary records was, men I $6 \mathrm{~g}$ alcohol (I 4 units, equivalent to fourteen single measures of spirits weekly) and women $78 \mathrm{~g}$ alcohol (10 units, equivalent to ten single gins weekly).

Smoking and exercise. Of the total sample $25 \%$ had never smoked, and by the age of retirement from work $47 \%$ had given up smoking. Of these, one-fifth had 


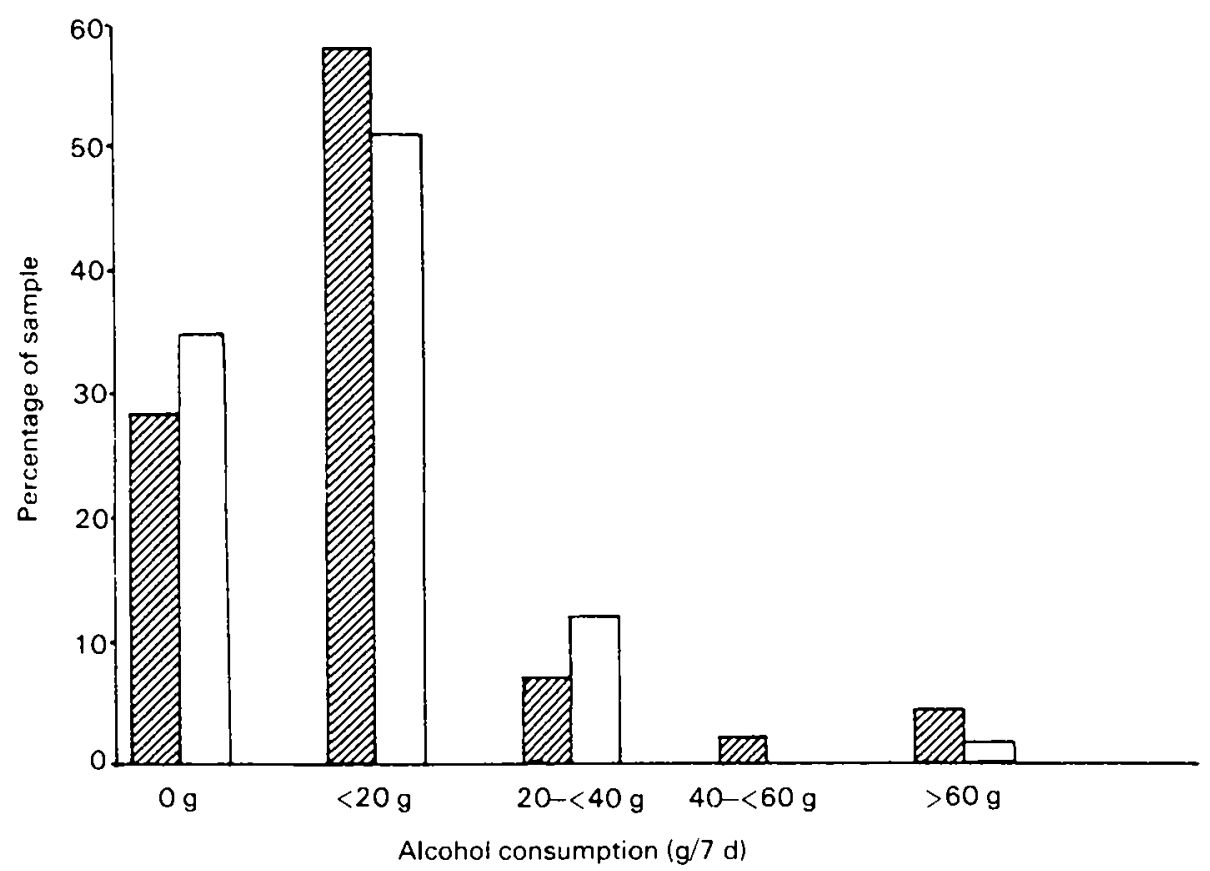

Fig. 6. Alcohol consumption during $7 \mathrm{~d}$ weighed and recorded dietary intakes of men and women approaching retirement from work. (घ) Men aged $63-64$ years, $n_{4} 6 ;(\square)$ women aged $5^{8-59}$ years, $n 66$.

spontaneously mentioned an increase in weight on giving up cigarettes. Of the $28 \%$ smoking at the time of the survey, $81 \%$ came from social classes III, IV and $\mathrm{V}$.

In the longitudinal study the Gerontology Nutrition Unit at Queen Elizabeth College will be examining the results on alcohol intake and cigarette smoking in conjunction with signs of stress. Over $25 \%$ of our sample were in a high-risk coding according to their answers to questions in the General Health Questionnaire (Goldberg, 1978), indicating anxiety and insomnia states.

The subjects were asked if they did regular brisk physical activity such as walking, jogging, cycling, swimming or other sports, including more strenuous types of gardening. In a separate question, an estimation was given of the time spent on such activities each week. For our total sample of $213,80 \%$ spent less than $\mathrm{r} / \mathrm{h} /$ week on brisk activities.

This could indicate the importance of the National Advisory Committee for Nutrition Education ( 1983 ) recommendations to keep up a greater physical activity right through the age-groups.

These preliminary findings indicate that preventive measures need to be taken at the earlier stage of retirement from work if our increasing elderly population is to enjoy a healthy retirement. 
This research is part of the Community programme under Regulation (EEC) nos. 2935/79 and $271 / 82$. The authors wish to thank British Petroleum and North Thames Gas for their essential co-operation, and their employees for participating so willingly in this detailed study. The authors are grateful to Dave Macfarlane, Computer Programer, Gerontology Nutrition Unit, for his valuable assistance.

\section{REFERENCES}

American Health Foundation (1979). Preventive Medicine 8, 61 2-678.

Bender, A. E., Magee, P. \& Nash, A. H. (1972). British Medical Fournal ii, 383.

Bingham, S., McNeil, N. L. \& Cummings, J. H. (1980). British fournal of Nutrition 45, 23-35.

Davies, L. \& Holdsworth, M. D. (1983). New Directions in Pre-Retirement Education. Stoke-on-Trent: Beth Johnson Foundation.

Department of Health and Social Security (1979). Recommended Daily Amounts of Food Energy and Nutrients for Groups of People in the UK. Report on Health and Social Subjects no. 15 London: H.M. Stationery Office.

Garrow, J. S. (1981). Treat Obesity Seriously. A Clinical Manual. London: ChurchillLivingstone.

Goldberg, D. (1978). Manual of the General Health Questionnaire. Windsor: NFER Publishing Co.

Holdsworth, M. D., Davies, L. \& Wilson, A. (1984). Human Nutrition: Applied Nutrition 38A, $132-137$.

National Advisory Committee on Nutrition Education (1983). Proposals for Nutritional Guidelines for Health Education in Britain. London: Health Education Council.

Royal College of Physicians (1983). Fournal of the Royal College of Physicians 1 7, 3-58.

Royal College of Physicians and British Cardiac Society (1976). Fournal of the Royal College of Physicians 10, $213-275$.

Southgate, D. A. T., Bingham, S. \& Robertson, J. (1978). Nature 274, 5 I-52.

Special Committee of the Royal College of Psychiatrists (1979). Alcohol and Alcoholism. London: Tavistock Publications.

Wilson, P. (1980). Drinking in England and Wales. London: H.M. Stationery Office.

World Health Organization (1982). Prevention of Coronary Heart Disease. Technical Report Series no. 678 . Geneva: WHO. 